\title{
Assessing constructive supervisor behavior: Development and evaluation of a brief follower- rated scale
}

\author{
Tago L. Mharapara ${ }^{1} \odot$ | Helena D. Cooper-Thomas ${ }^{1}$ | Ann Hutchison ${ }^{2}$ | \\ Jamie L. Callahan ${ }^{3}$
}

${ }^{1}$ Department of Management, AUT Business School, Auckland University of Technology, Auckland, New Zealand

${ }^{2}$ Department of Management and International Business, University of Auckland Business School, The University of Auckland, Auckland, New Zealand

${ }^{3}$ Leadership \& HRM Department, Newcastle Business School, Northumbria University Newcastle, Newcastle upon Tyne, UK

\section{Correspondence}

Tago L. Mharapara, Management Department, Auckland University of Technology, Auckland, New Zealand.

Email: t.mharapara@aut.ac.nz;

tagomharapara@gmail.com
Followers are thought to be keenly attuned to supervisor behaviors because these can affect their learning, well-being, and performance at work. However, a practical and empirically tested measure of constructive supervisor behaviors that are valued by followers is not available in the literature. We develop a Constructive Supervisor Behavior Scale (CSBS) that is suitable for human resource development purposes and we assess its psychometric properties across three studies. In Study 1, exploratory factor analysis is conducted on data collected from employees in New Zealand and the United States $(N=333)$. This resulted in a four-factor structure comprising ethical conduct, networking, clarifying, and recognizing behaviors. In Study 2, confirmatory factor analyses are used to assess the four-factor structure of the CSBS on New Zealand-based employees $(N=250)$. In Study 3, the convergent and discriminant validity of the CSBS are examined on office-based employees in the United States ( $N=342)$; additional measurement invariance analyses are conducted with the New Zealand and U.S. samples.

\section{KEYWORDS}

constructive supervisor behavior, leader development, measurement invariance, researcher-practitioner gap

\section{1 | INTRODUCTION}

Follower perceptions of leader behaviors in organizations have been linked to a range of follower outcomes including satisfaction with supervision (Jernigan \& Beggs, 2005), affective commitment (Djibo, Desiderio, \& Price, 2010), work engagement (De Clercq, Bouckenooghe, Raja, \& Matsyborska, 2014), and performance (Deluga, 1994). In a 
systematic review of research examining the relationship between leader behaviors and employee outcomes, Skakon, Nielsen, Borg, and Guzman (2010) showed that positive, or constructive, leader behaviors (e.g., support, feedback, and integrity) are related to employee affective well-being, reduced stress, and greater ability to cope with stress.

Given the positive individual and organizational effects of constructive leader behavior, it is no wonder that management and leadership training represent the biggest expenditure in many organizations' training and development portfolios (Association for Talent Development, 2017). Because of the costs (e.g., money, work disruption) involved with initiating a leader behavior development program, a prudent organization may want to take steps to maximize the benefit of these programs. From a performative perspective, mechanisms to more easily conduct a needs assessment would likely be welcomed measures to help achieve such maximization efforts. However, gaining a deeper awareness of these constructive behaviors for leaders themselves and a broader understanding of where and how these behaviors manifest within the organization can provide more than simply a financial return to both the individual and the organization.

While a variety of leader behavior measures exist (e.g., $360^{\circ}$ ) that can be adapted for gaining greater insights into individual and organizational development, these tend to be resource-intensive in terms of time and financial costs (Herd, Alagaraja, \& Cumberland, 2016; Wiley \& Lake, 2014). In this research, we detail the development of a short but rigorously derived measure of leader behavior that is associated with effectiveness. We contend that a brief measure is sorely needed and will be a boon for both human resource development (HRD) practitioners and scholars. As Callahan and Connor (2015) note, the ability to provide quantitative data can be particularly effective in initiating or cementing change, even in the face of power dynamics. Data derived from a short measure can be used at the organizational level to obtain management support for training, at the program level to identify areas for training content development, and at the individual level for leaders' self-awareness. For applied researchers, balancing the tension between relevance and rigor is an enduring challenge (Anderson, Herriot, \& Hodgkinson, 2001). A brief but psychometrically sound measure of effective leader behavior may increase organizations' willingness to collaborate with scholars because it levies minimal demands on employee time.

Thus, we develop a brief Constructive Supervisor Behavior Scale (CSBS) using contemporary scale development and abridging methods (Nielsen \& Abildgaard, 2012; Worthington \& Whittaker, 2006). We define constructive supervisor behavior as beneficial supervisor actions that followers value because they facilitate employee performance (individual, work unit, and organizational) and well-being. Our definition is derived from research on leader behavior associated with effectiveness (Hamlin \& Hatton, 2013; Yukl, 2012). We use the terms leader, leadership, and leader behavior to present and discuss theory. However, at the empirical level and in discussing findings from the current research, we use the term supervisor because it clearly identifies the direct leader of any follower respondent. Thus, a supervisor is a leader whose behavior influences the performance and well-being of a team, work unit, or organization (Skakon et al., 2010; Yukl, 2012).

\subsection{Theoretical context}

To understand the central role of constructive leader behavior in followers, we turn to the HRD literature because of its theoretical and empirical influence on leader behavior and development research. Empirical research in HRD has examined the nature of effective leader behavior (Kowske \& Anthony, 2007; Patel \& Hamlin, 2012) and categorized antecedents of effective leader behavior (Ardichvili, Jondle, \& Kowske, 2012; Ruiz, Hamlin, \& Carioni, 2016). Theoretical and conceptual work in HRD has attempted to delineate effective (constructive) leader behaviors and competencies (Cumberland, Herd, Alagaraja, \& Kerrick, 2016; Herd et al., 2016; Hezlett, 2008). Indeed, Kim and Callahan (2013) suggest that leadership, and its impact on learning, is the foundation of organizational performance. They postulate that leadership concepts from the transfer of learning and organizational learning literature can be combined to improve organizational performance. Because of the systemic nature of organizational learning, we begin with that lens to frame the importance of leader behavior for HRD professionals. 
To understand an organization's learning system, according to Schwandt and Marquardt (2000), it is pertinent to know how leadership is defined within the organization. If a leader has a relatively limited view of their role in the organization, they might resort to controlling and directing (i.e., task-oriented behavior) behavior. However, followers may also benefit from other constructive leader behaviors (i.e., relations, change, external, and ethically oriented) that enable them to meet their performance and well-being needs. This suggests that a leader should be attuned to follower needs even if they are not part of the leader's core job requirements, namely enabling direct reports to accomplish their tasks. From follower perspectives, it is plausible to assume that they pay close attention to leader behavior because it provides informational cues about behavior that is either implicitly condoned or explicitly endorsed by the organization (Dineen, Lewicki, \& Tomlinson, 2006). For followers, accurately observing and interpreting a supervisor's behavior is essential to surviving and flourishing within an organization (Gilbreath \& Benson, 2004).

Building upon the systemic foundations of Schwandt and Marquardt's (2000) organizational learning framework, Callahan and De Dávila (2004) developed a conceptual model of HRD action. This approach is useful for understanding actions (behaviors) that are important for organizations, and encompasses both organizational learning and leadership. The current study can be understood in relationship to core HRD actions as described by Callahan and De Dávila (2004).

Their Identity-Integration and Adaptation-Achievement (I-A) framework is an action-oriented heuristic consisting of four interconnected categories of action found in most social systems-identity, integration, adaptation, and achievement. The framework delineates the orientation of action in HRD and posits that identity and integration actions are geared toward the internal environment. Identity actions refer to how an individual maintains a unique culture and identity. For example, by modeling appropriate behavior (e.g., ethical conduct), a leader establishes norms and standards of behavior for followers to emulate. Integration actions refer to how an individual creates an integrated sense of identity for others. When leaders nurture and promote positive formal and informal communication pathways between themselves and their followers, they facilitate integration of followers into the work unit or organization. By finding novel ways to support, develop, or recognize followers, they effectively integrate employees into the workplace.

Adaptation and achievement actions are oriented toward the external environment (Callahan \& De Dávila, 2004). Adaptation actions are related to how an individual interacts with the external environment. For instance, a leader who is adept at external monitoring, networking, and advocacy can acquire resources that followers can use to address their performance and well-being needs. In addition to obtaining resources, a leader who can remove bureaucratic obstacles or defend followers from external threats is also likely to be perceived as effective. Achievement actions are related to how an individual uses resources to accomplish goals. Callahan and De Davila state that planning is an achievement action because it engages resources toward achieving future goals. A leader who consistently performs planning, clarifying, and problem-solving behaviors allows followers to accomplish work in an efficient and reliable manner.

In sum, HRD learning and development theory provides plausible explanatory mechanisms for the relationship between constructive leader behavior and follower outcomes. Specifically, theorists posit that followers are likely to experience better outcomes in terms of learning, performance, and well-being if leaders display constructive behavior that followers value.

\section{2 | Empirical context}

To classify leader behaviors associated with effectiveness, a range of classifications have been developed. These include the Taxonomy of Managerial Performance Requirements (Borman \& Brush, 1993), the Lay Model of Managerial Effectiveness (Cammock, Nilakant, \& Dakin, 1995), the Hyperdimensional Taxonomy of Managerial Competence (Tett, Guterman, Bleier, \& Murphy, 2000), the British Taxonomy of Perceived Managerial and Leadership Effectiveness (Hamlin \& Hatton, 2013), the Stress Management Competency Indicator Tool (Yarker, Lewis, \& DonaldsonFeilder, 2008), and the Hierarchical Behavior Taxonomy (HBT) (Yukl, 2012). Each classification was considered for 
the current research but the HBT was chosen because it is accompanied by an instrument with an especially strong history of empirical support behind its development.

The strengths of the HBT relative to previous leadership behavior models are outlined by Behrendt, Matz, and Göritz (2017): "(a) It includes detailed behavioral descriptions and abandons certain concepts that cannot be distinguished from their effects (e.g., charisma)" and "(b) It integrates similar behavioral concepts from different models into one systematic taxonomy, thereby eliminating many overlaps among behavioral concepts" (p. 233). The HBT provides an understanding of what leaders actually do that affects follower perceptions. Essentially, it captures the leadership aspects of supervisory work. Of course, managerial work includes other tasks and accountabilities, but the focus of the HBT, mirrored in our research, is on constructive leader behaviors in a supervisory situation.

Work by O'Donnell, Yukl, and Taber (2012) has shown that leader behaviors (supporting, delegating, and leading by example) as reported by followers were positively related to those followers' perceptions of the quality of the exchange relationship with the leader. More specifically, HBT leader behaviors have been shown to influence follower perceptions of effectiveness, affective commitment (Hassan, Mahsud, Yukl, \& Prussia, 2013), work unit performance (Yukl, Mahsud, Hassan, \& Prussia, 2013), and leader-member exchange (LMX) (Yukl, O'Donnell, \& Taber, 2009). The originators of the HBT argue that its leader behaviors are observable, distinct, measurable, and relevant to leaders in professional, sales, and technical roles (O'Donnell et al., 2012). Research participants have also been drawn from diverse industries, organizations, and occupations (Yukl et al., 2009).

As noted earlier, HRD theory suggests that followers' perceptions of supervisory behavior impact follower outcomes. These perceptions of supervisory (or leader) behavior can be mapped to core HRD actions that are grounded in concepts of learning and performance in organizations. Table 1 shows the similarities between the HBT and the I-A framework that provide a theoretical rationale for why we think constructive leader behaviors are relevant for followers.

Yukl (2012) and Yukl and Lepsinger (1991) developed the Managerial practices survey (MPS) to empirically test the HBT. The MPS has 60 items and therefore does not impose an onerous response burden; however, the processes associated with implementing the measure are time-consuming (G. Yukl, personal communication, October 28, 2012). Yukl recommends that employees undergo rater training to distinguish leader behavior. Following that, employees should be granted a period of six-to-eight weeks to systematically observe the leader while recording the

TABLE 1 Similarities of the I-A, HBT and ELQ

\begin{tabular}{|lcc|}
\hline I-A & HBT & ELQ \\
\hline Identity & & Ethically oriented behavior \\
\hline Integration & Relations-oriented behavior & Supporting \\
& Developing & \\
& Recognizing & Empowering \\
\hline Adaptation & External-oriented behavior \\
& Networking \\
& External monitoring \\
Representing & Pask-oriented behavior \\
Achievement & Planning \\
& Clarifying \\
Problem solving \\
Monitoring operations
\end{tabular}

Note. ELQ: Ethical Leadership Questionnaire; HBT: Hierarchical Behavior Taxonomy; I-A: Identity-Integration and Adaptation-Achievement. 
occurrence and frequency of relevant behaviors or incidents. This makes the MPS an unattractive option both for practitioners requiring an efficient needs assessment tool, and for scholars wanting a research instrument that can be combined with other measures.

Following validation work on the MPS, Yukl et al. (2013) subsequently identified the need to include leader ethical behaviors in the HBT. After controlling for task, relations, and change behaviors, Yukl et al. (2013) found that ethical leadership was a significant predictor of LMX and leader effectiveness, and explained additional variance beyond the MPS behaviors. Hence, they developed the ethical leadership questionnaire (ELQ) as a stand-alone measure to assess essential aspects of ethical leadership. To develop a brief measure that covers a broader range of instrumental behavior, we integrate ethical behaviors into our measure of constructive supervisor behavior.

Our aim is to produce a shorter measure with sound psychometric properties that can be used across various roles and industries without the need for rater training. Our methodology of developing an abridged measure of constructive leader behavior follows the methodology of similar endeavors by scholars developing shorter instruments from broader content coverage. For example, Nielsen and Abildgaard (2012) used a similar approach to develop a job-crafting measure for use with blue-collar workers. Through factor-analytic methods, the authors adapted a generic job-crafting instrument (Tims, Bakker, \& Derks, 2012) that has four dimensions and 21 items, and developed a job-crafting scale specific to blue-collar workers that has five dimensions and 15 items (Nielsen \& Abildgaard, 2012).

Leveraging the work done on the MPS and ELQ (Yukl et al., 2013; Yukl \& Lepsinger, 1991), we use a three-study methodology (Nielsen \& Abildgaard, 2012; Worthington \& Whittaker, 2006) to design a short scale, which we name the CSBS. In the first study, we use exploratory factor analysis (EFA) and parallel analysis to identify behaviors (factors) with the highest and most interpretable loadings (Brown, 2006). In the second study, we conduct a confirmatory factor analysis (CFA) on a second sample to evaluate the factor structure of the shortened scale and assess its construct validity. In the third study, we conduct a multigroup CFA on two geographically distinct samples to evaluate the shortened scale for measurement invariance.

While we acknowledge the effect of destructive (negative) leader behaviors on follower performance, our study is focused on identifying constructive leader behaviors that a learning system could act upon to enhance follower performance. By focusing our attention on constructive behavior, we exclude destructive behavior because it has been adequately addressed by other researchers (Thoroughgood, Padilla, Hunter, \& Tate, 2012; Thoroughgood, Tate, Sawyer, \& Jacobs, 2012), and it is outside the theoretical scope and practical purpose of our research. A robust inventory of destructive leader behavior is available in extant literature (Thoroughgood, Tate, et al., 2012).

\section{2 | STUDY 1}

In this section, we detail the methodology used to develop the CSBS.

\section{1 | Participants and procedure}

A sample of 333 participants (184 female and 149 male) in full-time office-based employment was recruited from New Zealand and the United States. One third of the data $(n=122)$ was drawn from the first author's social networking links-Linkedln.com and Facebook.com. Using the snowball technique (Heckathorn, 2002), contacts were asked to distribute a link to the questionnaire to their contacts. Approximately two-thirds of the sample $(n=211)$ were obtained through Qualtrics. From both samples, 483 participants started the survey and 333 completed all the questionnaire items for an overall response rate of $69 \%$. Across both samples, participants were removed because they failed to meet the criteria on the quality of responses (see Section 2.2.3).

The modal age range for participants was $26-35(n=104,31 \%)$, and most $(n=98,29 \%)$ of the participants reported having worked under their current manager or supervisor for 1-2 years. Participants identified as Asian 
(3\%), Black (12\%), Latino (2\%), White (80\%), and unspecified (3\%). Forty-three percent had attained a bachelor's degree, and $30 \%$ had attained a diploma, certificate, high school, or other qualifications. Participants were employed in a range of jobs including health care and social assistance, education and training, financial and insurance services, and manufacturing.

\section{2 | Measures}

\subsection{1 | Managerial practices survey}

The 60-item revised G16-4 MPS provided the foundational measure for supervisor behavior items (Yukl, Gordon, \& Taber, 2002). This survey has been used as a partial scale in other studies (O'Donnell et al., 2012; Yukl et al., 2009; Yukl, Wall, \& Lepsinger, 1990). Items were rated on a Likert scale ranging from 1 (not at all) to 5 (to a very great extent).

\subsection{2 | Ethical leadership questionnaire}

Four items from the ELQ were used to measure supervisor ethical conduct (Yukl et al., 2013). A sample item is "My supervisor sets an example of ethical behavior in his/her decisions and actions." The original scale uses an agreement response format. However, to capture frequency and be consistent with the MPS, items were rated on a Likert scale ranging from 1 (not at all) to 5 (to a very great extent).

\subsection{3 | Careless responding}

To preserve data quality, two criteria were imposed on the dataset to determine good complete cases. The first criterion involved two careless responding questions embedded into the survey (Meade \& Craig, 2012). The items were "I am paid bi-weekly by leprechauns" and "I do not understand a word of English." Cases were removed from the dataset if the participant did not provide the appropriate answer (i.e., disagree or strongly disagree). Results from an earlier pilot study indicated that respondents should spend at least 10 min completing the questionnaire, and this minimum completion time was the second criterion.

\subsection{Data analysis and results}

IBM Corp. Released 2013 (IBM SPSS Statistics for Windows, Version 22.0. Armonk, NY: IBM Corp.) was used to conduct an EFA using principal axis factoring to extract salient constructive supervisor behaviors, in an iterative manner. We retained items that had both substantive and conceptual relevance while systematically eliminating those that contributed to poorly defined factors (Brown, 2006), either showing low item loadings of less than 0.50 (Costello \& Osborne, 2005) on a factor, or that cross-loaded at more than 0.30 on two or more factors. Any such items were removed one at a time and the analysis was repeated. Factors on which only two or three items had salient (>0.50) loadings were also removed (Brown, 2006; Costello \& Osborne, 2005). Analyses were rerun and re-evaluated until all the items that did not define a given factor or that were cross-loaded were removed. This resulted in a four-factor structure, with each factor measured by four items loading at 0.70 or greater. This four-factor solution explained $77 \%$ of the variance. The final item loadings and the factors representing a CSBS are presented in Table 2.

The first factor of the CSBS is ethical conduct. Also known as ethical leadership in organizational behavior literature (Brown \& Trevino, 2006; Yukl et al., 2013), ethical conduct is supervisor behavior that demonstrates integrity, fairness, and the importance of consistency of words and deeds to followers. Networking is the second factor of the CSBS. Networking is an external-oriented behavior in which a supervisor actively builds her or his social capital to benefit themselves and her or his work unit. Networking is achieved through the development of relationships and alliances with external parties that can provide useful resources (Yukl, 2012). The third factor of the CSBS is clarifying, which is a task-oriented behavior that seeks to reduce or eliminate the ambiguity associated with a follower's 
TABLE 2 Item content and factor loadings for the CSBS in study 1

\begin{tabular}{llll} 
Factor & & & \\
\hline 1 & 2 & 3 & 4
\end{tabular}

\section{Ethical conduct}

\begin{tabular}{|c|c|c|c|c|c|}
\hline ETL01 & Sets an example of ethical behavior in his/her decisions and actions & 0.92 & -0.01 & -0.00 & -0.03 \\
\hline ETLO2 & Insists on doing what is fair and ethical even when it is not easy & 0.90 & -0.00 & 0.00 & -0.05 \\
\hline ETLO3 & Opposes the use of unethical practices to improve performance & 0.89 & 0.02 & -0.08 & -0.05 \\
\hline ETLO4 & Communicates clear ethical standards and guidelines for members & 0.72 & 0.06 & 0.23 & 0.06 \\
\hline \multicolumn{6}{|c|}{ Networking } \\
\hline NET01 & $\begin{array}{l}\text { Builds and maintains a wide network of contacts among peers and } \\
\text { outsiders }\end{array}$ & 0.08 & 0.94 & -0.04 & 0.04 \\
\hline NETO2 & $\begin{array}{l}\text { Attends social and professional events to meet people with useful } \\
\text { information }\end{array}$ & 0.02 & 0.83 & -0.01 & 0.02 \\
\hline NET03 & Joins social networks that include outsiders with useful information & -0.09 & 0.74 & 0.03 & -0.01 \\
\hline NETO4 & $\begin{array}{l}\text { Develops cooperative relations with people who can provide } \\
\text { resources and assistance }\end{array}$ & 0.07 & 0.73 & 0.02 & -0.14 \\
\hline \multicolumn{6}{|l|}{ Clarifying } \\
\hline CLA01 & $\begin{array}{l}\text { Clearly explains the job responsibilities and task assignments to } \\
\text { members }\end{array}$ & 0.07 & 0.03 & 0.86 & 0.06 \\
\hline CLAO2 & Explains what results are expected for a task or assignment & -0.03 & -0.00 & 0.86 & -0.04 \\
\hline CLA03 & $\begin{array}{l}\text { Explains the rules, policies, and standard procedures that must be } \\
\text { followed }\end{array}$ & 0.02 & 0.02 & 0.83 & 0.02 \\
\hline CLA04 & $\begin{array}{l}\text { Sets specific performance goals and deadlines for important } \\
\text { aspects of the work }\end{array}$ & -0.02 & -0.02 & 0.72 & -0.11 \\
\hline \multicolumn{6}{|c|}{ Recognizing } \\
\hline REC01 & $\begin{array}{l}\text { Provides recognition for good performance by the team or work } \\
\text { unit }\end{array}$ & -0.01 & -0.04 & 0.01 & -0.99 \\
\hline REC02 & $\begin{array}{l}\text { Provides recognition for member achievements or important } \\
\text { contributions }\end{array}$ & 0.02 & -0.01 & -0.02 & -0.96 \\
\hline RECO3 & Praises effective performance by members of the work unit & 0.11 & 0.02 & -0.01 & -0.84 \\
\hline REC04 & Recommends high-performing members for appropriate rewards & -0.03 & 0.12 & 0.10 & -0.74 \\
\hline
\end{tabular}

Note. CSBS: Constructive Supervisor Behavior Scale.

Factors loading at or greater than 0.70 are shown in boldface.

work (Rizzo, House, \& Lirtzman, 1970). Recognizing is the fourth factor of the CSBS, and represents a relationoriented behavior that captures a supervisor's willingness to provide contingent rewards (e.g., praise, compliments) upon the performance of commendable work by followers (Podsakoff, Todor, \& Skov, 1982). To assess the stability of the derived four-factor structure, a parallel analysis was conducted to determine the number of factors that could occur by chance with the same data parameters (O'Connor, 2000). Four eigenvalues (8.30, 1.59, 1.31, and 0.92) were greater than the raw data eigenvalues at the 95 th percentile $(0.54,0.43,0.35$, and 0.29$)$ providing further support for a four-factor solution.

Descriptive statistics and estimates of internal consistency (Cronbach's alpha) are shown in Table 3. The four factors of the CSBS each demonstrated excellent internal reliability $(\alpha \geq 0.90)$. Results from Study 1 suggested a fourfactor model of distinct constructive supervisor behaviors that followers reliably distinguish and rate as frequently or infrequently exhibited by supervisors.

To assess the new measure further, the stability of the four-factor structure of the CSBS and its construct validity was assessed on a second sample of employees. We conducted EFA followed by CFA with this second sample (Study 2) to minimize the possibility that chance factors account for the results (Costello \& Osborne, 2005; Jackson, Gillaspy, \& Purc-Stephenson, 2009). 
TABLE 3 Descriptive statistics and bivariate correlations between CSBS factors in study 1

\begin{tabular}{|c|c|c|c|c|c|c|c|}
\hline & M & $S D$ & 1 & 2 & 3 & 4 & 5 \\
\hline \multicolumn{8}{|l|}{ Study 1} \\
\hline \multicolumn{8}{|l|}{ 1. Gender } \\
\hline 2. Ethical conduct & 3.42 & 4.69 & -0.04 & $(0.94)$ & & & \\
\hline 3. Networking & 2.92 & 4.34 & $0.11 *$ & $0.46 * *$ & $(0.90)$ & & \\
\hline 4. Clarifying & 3.41 & 3.90 & 0.04 & $0.54 * *$ & $0.42 * *$ & (0.90) & \\
\hline 5. Recognizing & 3.09 & 4.81 & -0.08 & $0.65^{* *}$ & $0.59 * *$ & $0.53^{* *}$ & $(0.95)$ \\
\hline \multicolumn{8}{|l|}{ Study 2} \\
\hline \multicolumn{8}{|l|}{ 1. Gender } \\
\hline 2. Ethical conduct & 3.86 & 3.96 & $-0.16 *$ & $(0.93)$ & & & \\
\hline 3. Networking & 3.69 & 3.65 & $-0.15^{*}$ & $0.40 * *$ & $(0.90)$ & & \\
\hline 4. Clarifying & 3.55 & 3.89 & $-0.17 *$ & $0.71 * *$ & $0.38 * *$ & $(0.90)$ & \\
\hline 5. Recognizing & 3.57 & 4.22 & -0.10 & $0.69 * *$ & $0.46 * *$ & $0.65 * *$ & $(0.94)$ \\
\hline
\end{tabular}

Note. Study 1, $n=333$. Study 2, $n=250$. CSBS: Constructive Supervisor Behavior Scale. $* p<0.05$.; ** $p<0.01$.

\section{3 | STUDY 2}

This section details the methodology used to assess the stability and convergent validity of the CSBS.

\section{1 | Participants and procedure}

The sample comprised 250 participants (121 female and 129 male) employed in New Zealand. One third $(n=70)$ of participants was drawn from two New Zealand-based organizations. The first organization $(n=40)$ is a large infrastructure company operating in multiple sectors including transportation, energy, utilities, and communications. The second organization was the New Zealand Defense Force $(n=30)$. The same two-step careless responding criteria were used to screen participants (see Study 1). The remainder of the sample was collected using the snowball technique (Heckathorn, 2002). The first author approached New Zealand-based contacts on Linkedln.com and Facebook. com and asked them to forward a link to the survey to their contacts living and working in New Zealand. From all three New Zealand-based samples, 400 participants started the survey and 250 completed all the questionnaire items for an overall response rate of $63 \%$. Like Study 1, participants were removed because they failed to meet the criteria on the quality of responses.

In addition to the employees from the two organizations that participated in the study, the other respondents were employed in various industries. These included education and training, professional and support services, healthcare and social assistance, and financial and insurance services. The modal age range was 36-45 years old and $35 \%$ of the participants reported having worked under their current manager or supervisor for 1-2 years. The sample was $82 \%$ white, and highly educated ( $29 \%$ had a bachelor's degree, $32 \%$ had a postgraduate qualification).

\section{2 | Measures}

\subsection{1 | Constructive Supervisor Behavior Scale}

Participants completed the 16-item CSBS derived from Study 1, comprising four constructive supervisor behaviors of clarifying, recognizing, networking, and ethical conduct. Responses to all items of the CSBS were rated on a Likert scale ranging from 1 (not at all) to 5 (to a very great extent). See Study 1 measures section for a description of the careless responding items. 


\subsection{Data analysis and results}

MPLUS version 8 (Muthen \& Muthen, 2017) was used to test the hypothesized four-factor model of constructive supervisor behavior. There is a possibility of range restriction because incumbent supervisors may still be in their role because they generally display constructive supervisor behaviors. Therefore, we used a maximum likelihood estimator because it is robust to non-normal data from range restriction (Muthen \& Muthen, 2010). The items (indicators) assessing each of the four subscales of constructive supervisor behavior were modeled as loading onto distinct but correlated latent factors. Descriptive statistics and estimates of internal reliability are shown in Table 3 . Factors in the CSBS showed excellent internal reliability $(\alpha \geq 0.90)$.

As shown in Table 4, fit indices for the hypothesized four-factor model of the CSBS were $\chi^{2}(98)=134.80$, SRMR $=0.04$ (<0.06), RMSEA = 0.04 (<0.05), CFI = 0.99 (>0.96), and TLI = 0.98 (>0.96), demonstrating a good fit of the model to the data ( $\mathrm{Hu} \&$ Bentler, 1999). The quality of the measurement model is also supported by the high standardized values of the factor loadings (>0.77) (McNeish, An, \& Hancock, 2017). The hypothesized CSBS model was tested against two other plausible models (Mueller \& Hancock, 2008). The first comparison was made against a three-factor model in which the two highest correlating factors, ethical conduct and clarifying $(r=0.71)$, were combined. A second comparison was made against a one-factor model in which all 16 indicators measured one latent factor. The Akaike Information Criterion (AIC) was used to compare model fit for these non-nested models (Bozdogan, 1987; Mueller \& Hancock, 2008), with lower values indicating a better fit. The CSBS four-factor model (AIC $=8,751.90)$ fits the data better than both a three-factor model (AIC $=8,985.28$ ) and a single-factor model $(\mathrm{AIC}=9,818.30)$.

\subsection{Common method bias test}

The threat posed by method bias has been adequately addressed by several scholars in organizational research. For example, Williams, Hartman, and Cavazotte (2010) demonstrated that method factors can bias estimates of construct reliability and validity. If the variance that is due to method factors is not assessed or controlled for, it can result in erroneous conclusions regarding the adequacy of a scale's reliability and convergent validity. In our work, we follow the recommendations of organizational researchers (Podsakoff, MacKenzie, Lee, \& Podsakoff, 2003; Podsakoff, MacKenzie, \& Podsakoff, 2012) who have written extensively on this subject.

In designing our study questionnaire, we used procedural remedies (Podsakoff et al., 2003; Podsakoff et al., 2012) to measure and control for common method bias. We employed proximal separation between constructs, reworded some of the scale items to eliminate ambiguity, and provided study participants with an assurance of

TABLE 4 Fit indices for the four-factor CSBS model and alternative models in study 2

\begin{tabular}{|c|c|c|c|c|c|c|}
\hline & $\chi^{2}(d f)$ & AIC & CFI & TLI & SRMR & RMSEA \\
\hline \multicolumn{7}{|l|}{ Study 2} \\
\hline Hypothesized four-factor model & $134.80(98)$ & $8,751.90$ & 0.99 & 0.98 & 0.04 & 0.04 \\
\hline \multicolumn{7}{|l|}{ Alternative models } \\
\hline Three-factor model & 337.13 (101) & $8,985.28$ & 0.91 & 0.90 & 0.05 & 0.10 \\
\hline Single-factor model & $1,019.05$ (104) & $9,818.30$ & 0.66 & 0.61 & 0.12 & 0.19 \\
\hline \multicolumn{7}{|l|}{ Study 3} \\
\hline Hypothesized four-factor model & $215.00(98)$ & $11,865.30$ & 0.97 & 0.97 & 0.04 & 0.06 \\
\hline \multicolumn{7}{|l|}{ Alternative models } \\
\hline Three-factor model & $449.06(101)$ & $12,151.98$ & 0.92 & 0.90 & 0.04 & 0.10 \\
\hline Single-factor model & $1,306.79(104)$ & $13,262.83$ & 0.72 & 0.67 & 0.09 & 0.18 \\
\hline
\end{tabular}

Note. AIC: Akaike Information Criterion; CFI: 0.96; CSBS: Constructive Supervisor Behavior Scale; RMSEA: 0.05; SRMR: 0.06; TLI: 0.96 . 
response anonymity. Following data collection, we used two statistical remedies to assess the impact of common method bias on our hypothesized model (Podsakoff et al., 2003; Podsakoff et al., 2012). The first remedy was Harman's single-factor test that is described here in the model test. Results from Harman's single-factor test showed that the hypothesized four factor model fit the data better than the single-factor model. As an additional test of common method bias, we added a common latent factor into our hypothesized model. A comparison between the hypothesized four factor model and a model that included a common latent factor showed that the models did not differ significantly using the Satorra-Bentler scaled $\chi^{2}(11)=6.35, p=0.85$, providing evidence against the influence of common methods bias.

\section{5 | Construct validity}

Estimates from the factor correlations and standardized regression weights were used to calculate the average variance extracted (AVE), maximum shared variance (MSV), and average squared variance (ASV; Gaskin, 2015). The AVE estimate demonstrates convergent validity by indicating the amount of variation a latent construct explains in the observed variables to which it is theoretically related (Malhotra \& Dash, 2011). To establish discriminant validity, the AVE was compared to indicators of shared variance (MSV, ASV), where shared variance refers to the amount of variance a factor (e.g., clarifying) is able to explain in another factor (e.g., recognizing). Adequate discriminant validity exists when the AVE is greater than the MSV or the ASV (Hair, Tatham, Anderson, \& Black, 2006; Malhotra \& Dash, 2011). Results showed that the AVE for the four factors was 0.69 or greater providing adequate evidence for convergent validity. In addition, the AVE for each of the four factors was greater than the MSV and ASV, supporting the discriminant validity of each CSBS factor.

The global nature of work suggests that a number of organizations have subsidiaries, branches, or offices in other countries. Thus, it is relevant to study work relations and the experiences of employees under increasingly globalized conditions (Williams, Bradley, \& Erickson, 2013). A brief scale of constructive supervisor behavior that could be used in diverse geographical locations could be beneficial for global research. Therefore, having established the stability and convergent validity of the New Zealand-based sample in the current study, a key objective of the next study was to assess the performance and stability of the hypothesized four-factor model on a geographically distant sample, investigating measurement invariance (Cheung \& Rensvold, 2002; Widaman, Ferrer, \& Conger, 2010). Measurement invariance evaluates whether an instrument (scale) is measuring the same construct across specified groups (Cheung \& Lau, 2012; Cheung \& Rensvold, 2002; Widaman et al., 2010). For this, we used the New Zealand employee sample from Study 2 and a new sample from the United States recruited for Study 3. Also, we further examined the construct validity of the CSBS, repeating both the statistical analyses and adding assessments of theoretically related constructs (Campbell \& Fiske, 1959).

\section{STUDY 3}

This section details the methodology used to assess the performance of the CSBS on a geographically distant sample.

\section{1 | Construct validity}

One method for demonstrating convergent validity is to assess whether theoretically related constructs are also empirically related (Campbell \& Fiske, 1959). The four factors that emerged from Study 1, and supported in Study 2 , were ethical conduct, networking, clarifying, and recognizing. First, taking ethical conduct, this construct represents supervisor actions that communicate clear ethical guidelines and opposes the use of unethical practices. This is similar to Brown, Trevino, and Harrison (2005), who suggest that ethical leadership is an amalgamation of 
considerate, trustworthy, and fair behavior by a leader. Given the conceptual overlap of these two constructs, we advance the following hypothesis:

Hypothesis 1: There will be a positive relationship between supervisor ethical conduct (CSBS) and ethical leadership.

Second, networking in the CSBS represents behavior intended to build alliances and social capital to further the supervisor's interests, her or his team, and the organization. In their conceptualization of networking ability, Douglas and Ammeter (2004) suggest that networking ability is a political skill that individuals at any level use to effectively navigate organizational life. Thus, we propose the following hypothesis:

Hypothesis 2: There will be a positive relationship between supervisor networking (CSBS) and networking ability.

Clarifying behavior is the third construct in the CSBS. It represents supervisor behavior that is effective at explaining job responsibilities and standards of performance. This is similar to role clarity as conceptualized by Rizzo et al. (1970) who contend that adequate role clarity reduces or eliminates the ambiguity associated with the employee's work. Hence, we put forward the following hypothesis:

Hypothesis 3: There will be a positive relationship between supervisor clarifying (CSBS) and leader role clarity.

Recognizing is the fourth construct in the CSBS and it represents supervisor behavior that praises superior performance by others and recommends them for appropriate rewards. This construct is similar to contingent reward (Podsakoff, Todor, Grover, \& Huber, 1984), which refers to the awarding of desirable reinforcers (e.g., compliments) for commendable work performance. Leaders are generally vested with the power to distribute contingent rewards based on performance. Subsequently, we propose the following hypothesis:

Hypothesis 4: There will be a positive relationship between supervisor recognizing (CSBS) and leader contingent reward.

In addition, we sought to establish convergent validity of the CSBS scale at a more general level, relative to relationship quality between leaders and followers. More specifically, if the CSBS, at the behavioral level, reflects good quality relationships between supervisors and followers, then it should correlate with a measure of leader-follower relationship quality. LMX theory suggests that leaders develop an exchange with each of their followers, and the quality of these leader-member exchange relationships influences follower satisfaction, commitment, and performance (Dulebohn, Bommer, Liden, Brouer, \& Ferris, 2012). In measuring the effects of various antecedents on LMX, Dulebohn et al. found that leader behaviors and perceptions explained most of the variance. Therefore, it is plausible to suggest that the CSBS constructs represent behaviors that reflect the state of a supervisor-follower relationship. Thus, we advance the following hypotheses:

Hypothesis 5: There will be a positive relationship between leader-follower relationship quality (LMX) and the CSBS dimensions of (a) ethical leadership, (b) networking, (c) clarifying, and (d) recognizing.

Furthermore, we sought to investigate discriminant validity by assessing the relationship of the CSBS dimensions with theoretically unrelated constructs. Variables that are not theoretically expected to be related must be prespecified to establish discriminant validity (Cohen, 1996; Fornell \& Larcker, 1981). In this case, the CSBS should be applicable across demographic variables-that is, there should not be relationships of age, gender, or educational attainment of followers with their ratings of their supervisors. Therefore, we advance the following null hypothesis: 
Hypothesis 6: There will be no significant relationships between age, gender, or educational attainment with CSBS (a) ethical leadership, (b) networking, (c) clarifying, and (d) recognizing.

\section{2 | Measurement invariance}

Measurement invariance is assessed at three levels from least to most stringent (Meredith, 1993). First, configural invariance assesses the extent to which the basic factor structure and loading patterns of the CSBS hold across different groups (Horn, McArdle, \& Mason, 1983). Following this, metric invariance assesses whether participants in both samples have interpreted the scale items in the same way (Bollen, 1989). Last, scalar invariance is the most stringent assessment of measurement invariance and allows for the comparison of mean differences on the scores of the latent factors (Widaman \& Reise, 1997).

\section{3 | Participants and procedure}

Participants were obtained through Qualtrics and were working full-time in the United States. Participants were employed in a range of office-based jobs including healthcare and social assistance (14\%), education and training (13\%), professional and support services (11\%), financial and insurance services (9\%), and manufacturing (9\%). The modal age range was 36-45, and the most common tenure under the current supervisor was 7 years or more (26\%). Participants identified as Asian (5\%), Black (7\%), Latino (4\%), Middle Eastern (1\%), White (81\%), and unspecified (2\%). Regarding educational attainment, 50\% had attained a Bachelor's degree. From the 1,115 who began the survey, 342 had complete cases that also met the two-step screening criteria (see Section 2.2.3).

\section{4 | Measures}

Given the length of the questionnaire and the multiple assessment of similar constructs, the scales assessing convergent validity were presented in random order to minimize attempts at distortion (Schriesheim \& DeNisi, 1980) and measurement error attributable to boredom or fatigue (Podsakoff et al., 2003). As before, a Likert scale was used for the CSBS, ranging from 1 (not at all) to 5 (to a very great extent). All other items were rated on a Likert scale ranging from 1 (strongly disagree) to 7 (strongly agree).

\subsection{1 | Constructive Supervisor Behavior Scale}

The 16-item CSBS was used to measure the four constructive supervisor behaviors of clarifying, recognizing, networking, and ethical conduct (Table 4).

\subsection{2 | Role ambiguity}

Rizzo et al.'s (1970) 6-item role ambiguity scale was adapted from a self-report structure to a follower-report structure. An example item is: My supervisor... "clearly explains how much authority I have" and "lets me know exactly what is expected of me."

\subsection{3 | Contingent reward}

Podsakoff et al.'s (1984) 10-item contingent reward behavior scale was used to rate follower views of supervisor acknowledgment. Example items are: My line manager or supervisor... "always gives me positive feedback when I perform well" and "personally pays me a compliment when I do outstanding work." 


\subsection{4 | Network building}

The 6-item network building scale developed by Douglas and Ammeter (2004) was used to rate employee agreement with supervisor-networking behavior. The stems were adapted to correspond with the rest of the questionnaire and example items are: My line manager or supervisor... "is good at building relationships with influential people" and "is good at using connections and networks to make things happen at work."

\subsection{5 | Ethical leadership}

Ethical leadership was measured using the 10-item ethical leadership scale developed by Brown and Trevino (2006). Example items are: My line manager or supervisor... "disciplines employees who violate ethical standards" and "sets an example of how to do things the right way in terms of ethics."

\subsection{6 | Leader-member exchange multidimensional measure}

The 12-item leader-member exchange multidimensional measure (LMX-MDM) was used as a general measure of the quality of the leader-follower relationship (Liden \& Maslyn, 1998). Example items are: "My supervisor defends my work actions to a superior, even without complete knowledge of the issue in question" and "I admire my supervisor's professional skills."

\subsection{7 | Demographic variables}

Age, gender, and educational attainment variables were used to assess discriminant validity and to describe the sample. Age was indicated on a categorical scale ranging from 1 (18-25) to 6 (Over 65). Gender was indicated on a categorical scale ranging from 1 (Male) to 2 (Female). Educational attainment was indicated on a categorical scale where the options were 1 (Doctorate, e.g., PhD), 2 (Professional degree, e.g., M.D), 3 (Master's degree e.g., M.A.), 4 (Postgraduate degree), 5 (Bachelor's degree), 6 (Diploma), 7 (Certificate), 8 (High school), and 9 (No qualification).

\section{5 | DATA ANALYSIS AND RESULTS}

A CFA was conducted to test the hypothesized four-factor model of constructive supervisor behavior. Similar to Study 2, the four latent factors and the indicator (item) to factor loadings were specified a priori. The items assessing each of the subscales of constructive supervisor behavior were modeled as loading on distinct but correlated latent factors.

Descriptive statistics including bivariate correlations, means, $S D$, and estimates of internal reliability are shown in Table 5. Once again, factors in the CSBS showed excellent internal reliability $(\alpha \geq 0.90)$. As shown in Table 3, fit indices for the hypothesized four-factor model of the CSBS showed a good fit to the data: $\chi^{2}(98)=215.00$, RMSEA = $0.06, \mathrm{SRMR}=0.04$, and TLI $=0.97$. Standardized factor loadings were high $(>0.83)$.

The hypothesized CSBS model was again tested against two other empirically plausible models to determine the best fit. Note that the same set of alternative models developed in Study 2 was compared in Study 3. Specifically, the first comparison was against a three-factor model in which the two highest correlating factors, ethical conduct and clarifying $(r=0.77)$, were combined. The second comparison was against a model in which all 16 indicators measure one latent factor. Again, the CSBS four-factor model fit the data significantly better than the other two. Like Study 2, a comparison between the hypothesized four-factor model and a model that included a common latent factor showed that the models did not differ significantly using the Satorra-Bentler scaled $\chi^{2}(11)=8.60, p=0.66$, providing evidence against the influence of common methods bias. 
TABLE 5 Descriptive statistics and intercorrelations of the CSBS, other constructive leader behavior constructs and demographic variables in study 3

\begin{tabular}{|c|c|c|c|c|c|c|c|c|c|c|c|c|}
\hline Construct & 1 & 2 & 3 & 4 & 5 & 6 & 7 & 8 & 9 & 10 & 11 & 12 \\
\hline \multicolumn{13}{|l|}{ CSBS } \\
\hline 1. Clarifying & (0.93) & & & & & & & & & & & \\
\hline 2. Recognizing & 0.73 & $(0.95)$ & & & & & & & & & & \\
\hline 3. Networking & 0.59 & 0.65 & $(0.92)$ & & & & & & & & & \\
\hline 4. Ethical conduct & 0.77 & 0.72 & 0.58 & $(0.92)$ & & & & & & & & \\
\hline \multicolumn{13}{|l|}{$\begin{array}{l}\text { Other constructive leader } \\
\text { behavior constructs }\end{array}$} \\
\hline 1. Role clarity & 0.85 & 0.70 & 0.55 & 0.76 & (0.96) & & & & & & & \\
\hline 2. Contingent reward & 0.67 & 0.85 & 0.55 & 0.69 & 0.72 & $(0.97)$ & & & & & & \\
\hline 3. Networking & 0.71 & 0.69 & 0.77 & 0.64 & 0.68 & 0.63 & $(0.96)$ & & & & & \\
\hline 4. Ethical leadership & 0.76 & 0.78 & 0.58 & 0.86 & 0.80 & 0.80 & 0.68 & (0.96) & & & & \\
\hline 5. LMX-MDM & 0.72 & 0.77 & 0.57 & 0.78 & 0.74 & 0.81 & 0.67 & 0.86 & $(0.96)$ & & & \\
\hline \multicolumn{13}{|l|}{ Demographic variables } \\
\hline 1. Age & -0.10 & -0.14 & -0.09 & -0.03 & -0.01 & -0.07 & -0.11 & -0.36 & -0.32 & & & \\
\hline 2. Gender & -0.02 & -0.05 & -0.00 & -0.04 & -0.06 & -0.03 & -0.06 & -0.04 & -0.03 & 0.06 & & \\
\hline 3. Educational attainment & -0.00 & -0.05 & -0.03 & -0.00 & -0.04 & -0.05 & -0.03 & 0.03 & -0.03 & -0.03 & 0.14 & \\
\hline Mean & 3.62 & 3.36 & 3.24 & 3.66 & 4.90 & 4.81 & 4.98 & 5.12 & 5.17 & 3.24 & 1.51 & 5.08 \\
\hline$S D$ & 1.03 & 1.12 & 1.11 & 1.06 & 1.54 & 1.63 & 1.46 & 1.38 & 1.31 & 1.20 & 0.50 & 1.61 \\
\hline
\end{tabular}

Note. CSBS: Constructive Supervisor Behavior Scale; LMX-MDM: leader-member exchange multidimensional measure.

\section{1 | Construct validity}

In Study 3, construct validity was assessed in two ways. In the first method, a CFA model was first specified, and the output used to calculate the AVE, MSV, and ASV (Gaskin, 2015). Results showed that the AVE for the four factors was 0.75 or greater providing adequate evidence for convergent validity. In addition, the AVE for each of the four factors was greater than the MSV and ASV of the hypothesized model. This supports the discriminant validity of the four factors of the CSBS factors.

To assess for convergent validity using the second method, simple bivariate correlations were examined (Rowold \& Heinitz, 2007). Correlations between CSBS factors and facet measures assessing similar elements were high with a mean correlation of $0.83(r s=0.77-0.86)$. Also, all four factors of the CSBS were positively associated with a general measure of leader-member relationship quality (LMX-MDM) with a mean correlation of 0.71 $(r s=0.57-0.78)$. The strong positive associations between the CSBS factors, facet measures, and a general measure of the follower-leader relationship support the CSBS' construct validity.

Bivariate correlations were examined to assess for discriminant validity (Aarons, Ehrhart, \& Farahnak, 2014). As shown in Table 5, correlations between CSBS factors and demographic variables were weak; age $(r s=-0.03$ to -0.14 ), gender ( $r s=-0.00$ to -0.05 ), and educational attainment ( $r s=-0.00$ to -0.05 ). This further supports the discriminant validity of the CSBS.

\subsection{Model invariance testing}

Table 6 shows the results of two standard CFAs for each sample, New Zealand and United States, and for both samples combined $(N=592)$, the latter showing an excellent fit $\chi^{2}(220)=383.13$, SRMR $=0.04$, RMSEA $=0.06$, and $\mathrm{TLI}=0.98$. Measurement invariance assessment indicated that the CSBS showed similar properties in the New Zealand and U.S. samples. The tests for configural, metric, and scalar invariance assessments showed good fit to 
TABLE 6 Fit indices for the multigroup CFA assessing the invariance of the CSBS on a New Zealand and United States sample in study 3

\begin{tabular}{cllllllll} 
& $\chi^{2}$ & $d f$ & AIC & CFI & TLI & RMSEA & 90\% CI & SRMR \\
Standard CFAs & & & & & & & & \\
New Zealand & 134.80 & 98 & $8,751.90$ & 0.99 & 0.98 & 0.04 & $0.020,0.054$ & 0.04 \\
United States & 215.00 & 98 & $11,865.30$ & 0.97 & 0.97 & 0.06 & $0.048,0.070$ & 0.04 \\
Overall model & 383.13 & 220 & $20,596.75$ & 0.98 & 0.98 & 0.05 & $0.042,0.058$ & 0.04 \\
Multigroup CFA & & & & & & & & \\
Configural model & 351.88 & 196 & $20,617.20$ & 0.98 & 0.97 & 0.05 & $0.043,0.060$ & 0.04 \\
Metric model & 396.00 & 208 & $20,607.82$ & 0.98 & 0.97 & 0.05 & $0.043,0.060$ & 0.04 \\
Scalar model & 383.13 & 220 & $20,596.75$ & 0.98 & 0.98 & 0.05 & $0.042,0.058$ & 0.04 \\
\hline
\end{tabular}

Note. Metric against configural model, $\chi^{2}(12)=15.88, p=0.20$. Scalar against configural model, $\chi^{2}(24)=28.67, p=0.23$. Scalar against metric model, $\chi^{2}(12)=12.91, p=0.38$. Standard and Multigroup models estimated using Maximum Likelihood with robust error estimation (MLR). AIC: Akaike Information Criterion; CFA: confirmatory factor analysis; CFI: $0.96 ; \mathrm{Cl}$, confidence interval; CSBS: Constructive Supervisor Behavior Scale; RMSEA: 0.05; SRMR: 0.06; TLI: 0.96.

the data, with RMSEAs of 0.05 and SRMRs of 0.04 . This suggests that the basic factor structure and loading pattern of the CSBS are similar for the New Zealand and the U.S. samples. Also, chi-square difference tests on more constrained models that levied metric and scalar invariance did not differ in fit from the less stringent configural model: Metric versus configural model, $\chi^{2}(12)=15.88, p=0.20$; scalar versus configural model, $\chi^{2}(24)=28.67, p=0.23$; and scalar versus metric model, $\chi^{2}(12)=12.91, p=0.38$. This provides further evidence of the strong performance of the CSBS under restrictive assumptions.

\section{6 | DISCUSSION}

Drawing on data from several samples of employees, the results of three studies show that the newly developed CSBS is a viable way of measuring the behaviors theorized in the HBT. The CSBS makes a useful contribution by including ethical conduct alongside the HBT's other key behaviors, which are clarifying, recognizing, and networking. This inclusion of ethical conduct in one combined scale has not previously been achieved. The CSBS is, therefore, not only valuable because of its brevity, but also because of its widened scope.

In terms of the importance of these behaviors, extant research has shown that leaders who use a combination of these behaviors, such as contingent reward and management-by-exception, elicit high levels of satisfaction and commitment from followers (Gavan O'Shea, Foti, Hauenstein, \& Bycio, 2009). Follower perceptions of constructive leader behavior have also been linked to follower performance (Shanock \& Eisenberger, 2006). Our newly developed scale, then, provides an accessible window to identifying constructive supervisor behavior. Now that four CSBS behaviors have emerged through our analyses, it is appropriate to describe them in more detail.

Supervisor-clarifying behavior is the first dimension to be identified in our study. By providing role clarity, a supervisor addresses followers' need for competence by being clear on what needs to be accomplished and how it should be done. Research has demonstrated a negative link between role ambiguity and job attitudes (Fisher \& Gitelson, 1983), and job performance (Tubre \& Collins, 2000). Other researchers have identified a positive association between role ambiguity and depression (Schmidt, Roesler, Kusserow, \& Rau, 2014). Taken together, these findings suggest that followers praise supervisor-clarifying behavior because it promotes positive job attitudes, it is associated with improved work performance, and it may lessen stress and anxiety.

Recognizing behavior was identified as a key supervisor behavior; it is valuable because it tells followers that their performance is appreciated by senior members of the organization and provides followers with positive feedback on their competence (Ryan \& Deci, 2000). Research suggests that employees are especially responsive to recognition that is timely, specific, frequent, and accurate (Luthans, 2000; Wiley \& Kowske, 2012). Supervisors are best 
positioned to provide tailored recognition because of their frequent interaction with followers. Therefore, it can be argued that supervisor-recognizing behavior motivates future job performance, learning, commitment, and intent to stay in followers.

The emergence of networking as a salient supervisor-provided resource corroborates the findings from Douglas and Ammeter's (2004) work on political skill and leader performance. They found networking ability, a dimension of political skill, was a predictor of leader performance as rated by others. A supervisor who is adept at networking builds and maintains a diverse network of contacts that can provide resources and assistance. In so doing, the supervisor accrues social capital that followers can then access to accomplish their own tasks. A supervisor with privileged access (through networking) is an asset to a follower because she or he can leverage her or his network for additional resources when needed. For example, followers of supervisors with significant social capital may experience less bureaucracy in trying to access additional resources when the need arises (Klein \& Kim, 1998).

Work done by Brown et al. (2005) provides insight into the emergence of ethical conduct as a key supervisor behavior. Followers value an ethical supervisor because it means behavior is more predictable (Scandura, 1997), and the supervisor provides guidance to followers of what is and is not appropriate behavior. Meta-analytic research has shown a positive link between the perceived behavioral integrity of managers and employee satisfaction with their job and their leader (Davis \& Rothstein, 2006). Taken together, supervisor ethical conduct is a resource that provides followers with clarity for ethically challenging scenarios and the basis for integrity at work.

Drawing on Yukl's (2012) effective leadership framework, which has been acknowledged as providing a useful HRD-relevant perspective on leadership (Park, Jeong, Jang, Yoon, \& Lim, 2018), the current research adds credence to the notion that interpersonal actions are the key to favorable follower perceptions of leader behavior. In addition, leader ethical conduct is a salient leader behavior that is incorporated under the personal traits and values theme of global leadership (Park et al., 2018).

\section{1 | Potential applications of the CSBS}

The CSBS is a short and practical measure of desired supervisor behavior from followers working in organizational contexts. Compared to the MPS from which it is derived (Yukl et al., 2002), the CSBS is shorter, measuring fewer behaviors with the benefit that raters (followers) can distinguish these without specific training or extensive observation.

Furthermore, the CSBS also benefits practitioners. The CSBS contains four generic or universal behaviors that are characteristic of effective managers in a variety of occupational sectors across geographically distinct samples. Thus, the CSBS can be used by HRD professionals for a variety of diagnostic and intervention purposes. Because of its brevity, the CSBS is an appealing tool for HRD professionals who want to strengthen the leadership base within their organizations. A brief instrument does not convey a message that the instrument alone is the sole measure of leadership capability; the use of CSBS can provide a window into individual leaders' behaviors, enabling individuals to engage in the important reflective work, which can build upon their potential strengths and address their development needs as leaders. This would be similar to pulse surveys used to assess organizational culture. Also, such an instrument could be used to create a profile of the leadership capabilities of the organization by distributing the tool to all leaders within a given organization, and then developing normative data from the results. As a diagnostic tool, such an instrument could reveal patterns of leadership behaviors that serve as signals for deeper exploration into individual and systemic issues. For example, if rules, policies, and procedures are consistently rated low (CLA03), this provides an opportunity to explore factors in the organization that may be behind this. For example, if investigation reveals the leader does not know the rules, then training might be in order; on the other hand, perhaps the rules, policies, and procedures are not explained by the leader because they were thought to be obvious; this feedback is helpful both to the leader, and also the organization, which can ensure they are accessible, and communicate them more consistently. 
The CSBS represents pragmatic science in that it addresses the needs of both academics and human resource professionals (Anderson et al., 2001). From an applied perspective, a concise measure of constructive leader behavior such as the CSBS is an attractive option. Organizations have a host of other priorities other than research, and therefore academics seeking access and collaboration will increase their chance of access if they use short survey instruments that minimize disruptions to employees' normal work functions (Fisher, Matthews, \& Gibbons, 2016). Furthermore, a short scale of constructive leader behavior allows researchers to measure focused leader behavior within larger multivariate studies without making the survey questionnaire too long (Nenkov, Morrin, Schwartz, Ward, \& Hulland, 2008). Not only do longer questionnaires take more time to complete, they tend to have more missing data and higher refusal rates (Stanton, Sinar, Balzer, \& Smith, 2002). Short instruments are also more easily embedded into mixed method studies that allow for both breadth and depth of data collection.

\subsection{Strengths and limitations}

In the three studies that describe the design and psychometric evaluation of the CSBS, we have taken a thorough approach, being careful to follow scholars' recommendations regarding the shortening of scales. These recommendations include preserving the content coverage of each specific factor, assessing for adequate internal reliability, and assessing for adequate construct validity and scale invariance in geographically distinct samples (Smith, McCarthy, \& Anderson, 2000; Stanton et al., 2002). However, it should be noted that this is the first iteration of a brief scale that seeks to measure the occurrence of constructive leader behavior by followers in organizational settings. Both practitioners and researchers are invited to use the CSBS with diverse samples in its current or adapted formats to determine whether it can be shortened further or if new items are warranted.

Our work aligns well with the cross-cultural body of work by Hamlin (2004) and Hamlin and Hatton (2013) who have shown that employees in different countries identify effective and ineffective leader behaviors in much the same way. The CSBS instrument complements this work due to its brevity, which makes it more accessible and easier to use for helping leaders reflect on their leadership behaviors. Yet, future supervisor-follower research using the CSBS would benefit from studying samples from different cultures. For example, in China, paternalistic leadership is prevalent in business organizations (Cheng, Chou, Wu, Huang, \& Farh, 2004). Would the same CSBS behaviors be retained in Chinese business contexts or would different behaviors emerge?

It is important to note that the CSBS does not measure all the behaviors that may be of interest to a variety of scholars and practitioners. A brief, rigorous, and broadly applicable measure of constructive supervisor behavior will, by definition, exclude some behavior. For example, the CSBS does not include supervisor behaviors such as empowering others, monitoring performance, or proposing an innovative strategy (Patel \& Hamlin, 2012; Yukl, 2012). Thus, while the aim of the CSBS is to be brief, rigorous, and useful across contexts, we acknowledge that this provides a narrow view that is focused on key behaviors. Practitioners may wish to supplement the CSBS with other measures targeted at behaviors of concern, which may be positive or negative. Yet in this regard, the CSBS can provide a stable core. In particular, we emphasize that the CSBS is likely to provide good quality data through two means. First, followers are asked to rate supervisors only on behaviors they are likely to have observed. Asking for ratings on behaviors that are infrequent or unobservable to followers would compromise data quality. Second, methods research suggests that lesser-known constructs are better measured by scales with at least three items as a minimum for accurate and stable measurement (MacCallum, Widaman, Zhang, \& Hong, 1999).

In conclusion, the CSBS is a tool for followers to rate supervisor behavior that is associated with individual, work unit, or team effectiveness. It is a brief scale that can be used by most employees across a variety of occupational sectors. The CSBS sits neatly between commercially oriented survey tools that can lack rigor, and extensive but time-consuming research measures; in contrast, the CSBS offers both rigor and relevance. Thus, we contend that it is a useful development tool for those who research supervisory behavior as well as those who seek to understand or improve factors associated with leadership behavior in their organizations. 


\section{ORCID}

Tago L. Mharapara (D) https://orcid.org/0000-0003-3781-553X

\section{REFERENCES}

Aarons, G. A., Ehrhart, M. G., \& Farahnak, L. R. (2014). The implementation leadership scale (ILS): Development of a brief measure of unit level implementation leadership. Implementation Science, 9(1), 1-18. https://doi.org/10. 1186/1748-5908-9-45

Anderson, N., Herriot, P., \& Hodgkinson, G. P. (2001). The practitioner-researcher divide in industrial, work and organizational (IWO) psychology: Where we are now, and where do we go from here? Journal of Occupational and Organizational Psychology, 74, 391-411. https://doi.org/10.1348/096317901167451

Ardichvili, A., Jondle, D., \& Kowske, B. (2012). Minding the gap: Exploring differences in perceptions of ethical business cultures among executives, mid-level managers and non-managers. Human Resource Development International, 15, 337-352. https://doi.org/10.1080/13678868.2012.687625

Association for Talent Development. (2017). State of the industry (Vol. 1). Alexandria, VA: ATD Research.

Behrendt, P., Matz, S., \& Göritz, A. S. (2017). An integrative model of leadership behavior. The Leadership Quarterly, 28, 229-244. https://doi.org/10.1016/j.leaqua.2016.08.002

Bollen, K. A. (1989). Structural equations with latent variables. New York, NY: Wiley.

Borman, W. C., \& Brush, D. H. (1993). More progress toward a taxonomy of managerial performance requirements. Human Performance, 6, 1-21. https://doi.org/10.1207/s15327043hup0601_1

Bozdogan, H. (1987). Model selection and Akaike's information criterion (AIC): The general theory and its analytical extensions. Psychometrika, 52, 345-370. https://doi.org/10.1007/BF02294361

Brown, M. E., \& Trevino, L. K. (2006). Ethical leadership: A review and future directions. The Leadership Quarterly, 17, 595-616. https://doi.org/10.1016/j.leaqua.2006.10.004

Brown, M. E., Trevino, L. K., \& Harrison, D. A. (2005). Ethical leadership: A social learning perspective for construct development and testing. Organizational Behavior and Human Decision Processes, 97, 117-134. https://doi.org/10.1016/j.obhdp. 2005.03.002

Brown, T. A. (2006). Confirmatory factor analysis for applied research. New York, NY: Guilford Press.

Callahan, J. L., \& Connor, G. (2015). The competing interests of paradigm and praxis in critical HRD research: Incorporating quantitative methods to enact critical practice. In M. Saunders \& P. Tosey (Eds.), Handbook of HRD research methods (pp. 311-324). Surrey, England: Edward Elgar.

Callahan, J. L., \& De Dávila, T. D. (2004). An impressionistic framework for theorizing about human resource development. Human Resource Development Review, 3, 75-95. https://doi.org/10.1177/1534484303261229

Cammock, P., Nilakant, V., \& Dakin, S. (1995). Developing a lay model of managerial effectiveness: A social constructionist perspective. Journal of Management Studies, 32, 443-474. https://doi.org/10.1111/j.1467-6486.1995.tb00784.x

Campbell, D. T., \& Fiske, D. W. (1959). Convergent and discriminant validation by the multitrait-multimethod matrix. Psychological Bulletin, 56, 81-105. https://doi.org/10.1037/h0046016

Cheng, B., Chou, L., Wu, T., Huang, M., \& Farh, J. (2004). Paternalistic leadership and subordinate responses: Establishing a leadership model in Chinese organizations. Asian Journal of Social Psychology, 7, 89-117. https://doi.org/10.1111/j. 1467-839X.2004.00137.x

Cheung, G. W., \& Lau, R. S. (2012). A direct comparison approach for testing measurement invariance. Organizational Research Methods, 15, 167-198. https://doi.org/10.1177/1094428111421987

Cheung, G. W., \& Rensvold, R. B. (2002). Evaluating goodness-of-fit indexes for testing measurement invariance. Structural Equation Modeling: A Multidisciplinary Journal, 9, 233-255. https://doi.org/10.1207/S15328007SEM0902_5

Cohen, A. (1996). On the discriminant validity of the Meyer and Allen measure of organizational commitment: How does it fit with the work commitment construct? Educational and Psychological Measurement, 56, 494-503. https://doi.org/10. $1177 / 0013164496056003011$

Costello, A. B., \& Osborne, J. W. (2005). Best practices in exploratory factor analysis: Four recommendations for getting the most from your analysis. Practical Assessment, Research and Evaluation, 10(7), 1-9.

Cumberland, D. M., Herd, A., Alagaraja, M., \& Kerrick, S. A. (2016). Assessment and development of global leadership competencies in the workplace: A review of literature. Advances in Developing Human Resources, 18, 301-317. https://doi. org/10.1177/1523422316645883

Davis, A. L., \& Rothstein, H. R. (2006). The effects of the perceived behavioral integrity of managers on employee attitudes: A meta-analysis. Journal of Business Ethics, 67, 407-419. https://doi.org/10.1007/s10551-006-9034-4

De Clercq, D., Bouckenooghe, D., Raja, U., \& Matsyborska, G. (2014). Servant leadership and work engagement: The contingency effects of leader-follower social capital. Human Resource Development Quarterly, 25, 183-212. https://doi.org/10. 1002/hrdq. 21185

Deluga, R. J. (1994). Supervisor trust building, leader-member exchange and organizational citizenship behaviour. Journal of Occupational and Organizational Psychology, 67, 315-326. https://doi.org/10.1111/j.2044-8325.1994.tb00570.x 
Dineen, B. R., Lewicki, R. J., \& Tomlinson, E. C. (2006). Supervisory guidance and behavioral integrity: Relationships with employee citizenship and deviant behavior. Journal of Applied Psychology, 91, 622-635. https://doi.org/10. 1037/0021-9010.91.3.622

Djibo, I. J. A., Desiderio, K. P., \& Price, N. M. (2010). Examining the role of perceived leader behavior on temporary employees' organizational commitment and citizenship behavior. Human Resource Development Quarterly, 21, 321-342. https://doi.org/10.1002/hrdq.20049

Douglas, C., \& Ammeter, A. P. (2004). An examination of leader political skill and its effect on ratings of leader effectiveness. The Leadership Quarterly, 15, 537-550. https://doi.org/10.1016/j.leaqua.2004.05.006

Dulebohn, J. H., Bommer, W. H., Liden, R. C., Brouer, R. L., \& Ferris, G. R. (2012). A meta-analysis of antecedents and consequences of leader-member exchange. Journal of Management, 38, 1715-1759. https://doi.org/10. $1177 / 0149206311415280$

Fisher, C. D., \& Gitelson, R. (1983). A meta-analysis of the correlates of role conflict and ambiguity. Journal of Applied Psychology, 68, 320-333. https://doi.org/10.1037/0021-9010.68.2.320

Fisher, G. G., Matthews, R. A., \& Gibbons, A. M. (2016). Developing and investigating the use of single-item measures in organizational research. Journal of Occupational Health Psychology, 21, 3-23. https://doi.org/10.1037/a0039139

Fornell, C., \& Larcker, D. F. (1981). Evaluating structural equation models with unobservable variables and measurement error. Journal of Marketing Research, 18, 39-50. https://doi.org/10.2307/3151312

Gaskin, J. E. (2015). Gaskinations statwiki. Retrieved from http://statwiki.kolobkreations.com/index.php?title=Main_Page

Gavan O'Shea, P., Foti, R. J., Hauenstein, N. M. A., \& Bycio, P. (2009). Are the best leaders both transformational and transactional? A pattern-oriented analysis. Leadership, 5, 237-259. https://doi.org/10.1177/1742715009102937

Gilbreath, B., \& Benson, P. G. (2004). The contribution of supervisor behaviour to employee psychological well-being. Work and Stress, 18, 255-266. https://doi.org/10.1080/02678370412331317499

Hair, J. F., Tatham, R. L., Anderson, R. E., \& Black, W. (2006). Multivariate data analysis. Upper Saddle River, NJ: Pearson Prentice Hall.

Hamlin, R. G. (2004). In support of universalistic models of managerial and leadership effectiveness: Implications for HRD research and practice. Human Resource Development Quarterly, 15, 189-215. https://doi.org/10.1002/hrdq.1098

Hamlin, R. G., \& Hatton, A. (2013). Toward a British taxonomy of perceived managerial and leadership effectiveness. Human Resource Development Quarterly, 24, 365-406. https://doi.org/10.1002/hrdq.21163

Hassan, S., Mahsud, R., Yukl, G. A., \& Prussia, G. E. (2013). Ethical and empowering leadership and leader effectiveness. Journal of Managerial Psychology, 28, 133-146. https://doi.org/10.1108/02683941311300252

Heckathorn, D. D. (2002). Respondent-driven sampling II: Deriving valid population estimates from chain-referral samples of hidden populations. Social Problems, 49, 11-34. https://doi.org/10.1525/sp.2002.49.1.11

Herd, A. M., Alagaraja, M., \& Cumberland, D. M. (2016). Assessing global leadership competencies: The critical role of assessment centre methodology. Human Resource Development International, 19, 27-43. https://doi.org/10.1080/13678868. 2015.1072125

Hezlett, S. A. (2008). Using multisource feedback to develop leaders: Applying theory and research to improve practice. Advances in Developing Human Resources, 10, 703-720. https://doi.org/10.1177/1523422308322271

Horn, J. L., McArdle, J. J., \& Mason, R. (1983). When is invariance not invarient: A practical scientist's look at the ethereal concept of factor invariance. Southern Psychologist, 1, 179-188.

Hu, L., \& Bentler, P. M. (1999). Cutoff criteria for fit indexes in covariance structure analysis: Conventional criteria versus new alternatives. Structural Equation Modeling: A Multidisciplinary Journal, 6, 1-55. https://doi.org/10. 1080/10705519909540118

Jackson, D. L., Gillaspy, J. A., Jr., \& Purc-Stephenson, R. (2009). Reporting practices in confirmatory factor analysis: An overview and some recommendations. Psychological Methods, 14, 6-23. https://doi.org/10.1037/a0014694

Jernigan, I. E., \& Beggs, J. M. (2005). An examination of satisfaction with my supervisor and organizational commitment. Journal of Applied Social Psychology, 35, 2171-2192. https://doi.org/10.1111/j.1559-1816.2005.tb02214.x

Kim, J., \& Callahan, J. L. (2013). Finding the intersection of the learning organization and learning transfer: The significance of leadership. European Journal of Training and Development, 37, 183-200. https://doi.org/10. 1108/03090591311301680

Klein, H. J., \& Kim, J. S. (1998). A field study of the influence of situational constraints, leader-member exchange, and goal commitment on performance. Academy of Management Journal, 41, 88-95. https://doi.org/10.2307/256900

Kowske, B. J., \& Anthony, K. (2007). Towards defining leadership competence around the world: What mid-level managers need to know in twelve countries. Human Resource Development International, 10, 21-41. https://doi.org/10. 1080/13678860601170260

Liden, R. C., \& Maslyn, J. M. (1998). Multidimensionality of leader-member exchange: An empirical assessment through scale development. Journal of Management, 24, 43-72. https://doi.org/10.1016/S0149-2063(99)80053-1

Luthans, K. (2000). Recognition: A powerful, but often overlooked, leadership tool to improve employee performance. Journal of Leadership and Organizational Studies, 7, 31-39. https://doi.org/10.1177/107179190000700104

MacCallum, R. C., Widaman, K. F., Zhang, S., \& Hong, S. (1999). Sample size in factor analysis. Psychological Methods, 4 , 84-99. https://doi.org/10.1037/1082-989X.4.1.84 
Malhotra, N. K., \& Dash, S. (2011). Marketing research: An applied approach (6th ed.). Upper Saddle River, NJ: Pearson Education.

McNeish, D., An, J., \& Hancock, G. R. (2017). The thorny relation between measurement quality and fit index cutoffs in latent variable models. Journal of Personality Assessment, 99, 1-10. https://doi.org/10.1080/00223891.2017.1281286

Meade, A. W., \& Craig, S. B. (2012). Identifying careless responses in survey data. Psychological Methods, 17, 437-455. https://doi.org/10.1037/a0028085

Meredith, W. (1993). Measurement invariance, factor analysis and factorial invariance. Psychometrika, 58, 525-543. https:// doi.org/10.1007/BF02294825

Mueller, R. O., \& Hancock, G. R. (2008). Best practices in structural equation modeling. In J. W. Osborne (Ed.), Best practices in quantitative methods (pp. 488-508). Thousand Oaks, CA: Sage.

Muthén, L. K., \& Muthén, B. O. (2017). Mplus user's guide (8th ed.). Los Angeles, CA: Muthén \& Muthén.

Muthen, L. K., \& Muthen, B. O. (2010). Mplus user's guide (7th ed.). Los Angeles, CA: Muthen \& Muthen.

Nenkov, G. Y., Morrin, M., Schwartz, B., Ward, A., \& Hulland, J. (2008). A short form of the maximization scale: Factor structure, reliability and validity studies. Judgment and Decision Making, 3, 371-388.

Nielsen, K., \& Abildgaard, J. S. (2012). The development and validation of a job crafting measure for use with blue-collar workers. Work and Stress, 26, 365-384. https://doi.org/10.1080/02678373.2012.733543

O'Connor, B. P. (2000). SPSS and SAS programs for determining the number of components using parallel analysis and Velicer's MAP test. Behavior Research Methods, Instruments, \& Computers, 32, 396-402. https://doi.org/10.3758/ BF03200807

O'Donnell, M., Yukl, G. A., \& Taber, T. (2012). Leader behavior and LMX: A constructive replication. Journal of Managerial Psychology, 27, 143-154. https://doi.org/10.1108/02683941211199545

Park, S., Jeong, S., Jang, S., Yoon, S. W., \& Lim, D. H. (2018). Critical review of global leadership literature: Toward an integrative global leadership framework. Human Resource Development Review, 17, 95-120. https://doi.org/10. $1177 / 1534484317749030$

Patel, T., \& Hamlin, R. G. (2012). Deducing a taxonomy of perceived managerial and leadership effectiveness: A comparative study of effective and ineffective managerial behaviour across three EU countries. Human Resource Development International, 15, 571-587. https://doi.org/10.1080/13678868.2012.726539

Podsakoff, P. M., MacKenzie, S. B., Lee, J., \& Podsakoff, N. P. (2003). Common method biases in behavioral research: A critical review of the literature and recommended remedies. Journal of Applied Psychology, 88, 879-903. https://doi.org/10. 1037/0021-9010.88.5.879

Podsakoff, P. M., MacKenzie, S. B., \& Podsakoff, N. P. (2012). Sources of method bias in social science research and recommendations on how to control it. Annual Review of Psychology, 63, 539-569. https://doi.org/10.1146/annurev-psych120710-100452

Podsakoff, P. M., Todor, W. D., Grover, R. A., \& Huber, V. L. (1984). Situation modifiers of leader reward and punishment behaviors: Fact or fiction? Organizational Behavior and Human Performance, 34, 21-63. https://doi.org/10. 1016/0030-5073(84)90036-9

Podsakoff, P. M., Todor, W. D., \& Skov, R. (1982). Effects of leader contingent and noncontingent reward and punishment behaviors on subordinate performance and satisfaction. Academy of Management Journal, 25, 810-821. https://doi. org $/ 10.2307 / 256100$

Rizzo, J. R., House, R. J., \& Lirtzman, S. I. (1970). Role conflict and ambiguity in complex organizations. Administrative Science Quarterly, 15, 150-163. https://doi.org/10.2307/2391486

Rowold, J., \& Heinitz, K. (2007). Transformational and charismatic leadership: Assessing the convergent, divergent and criterion validity of the MLQ and the CKS. The Leadership Quarterly, 18, 121-133. https://doi.org/10.1016/j.leaqua.2007. 01.003

Ruiz, C. E., Hamlin, R. G., \& Carioni, A. (2016). Behavioural determinants of perceived managerial and leadership effectiveness in Argentina. Human Resource Development International, 19, 267-288. https://doi.org/10.1080/13678868.2016. 1147778

Ryan, R. M., \& Deci, E. L. (2000). Self-determination theory and the facilitation of intrinsic motivation, social development, and well-being. American Psychologist, 55, 68-78. https://doi.org/10.1037/0003-066X.55.1.68

Scandura, T. A. (1997). Mentoring and organizational justice: An empirical investigation. Journal of Vocational Behavior, 51, 58-69.

Schmidt, S., Roesler, U., Kusserow, T., \& Rau, R. (2014). Uncertainty in the workplace: Examining role ambiguity and role conflict, and their link to depression-A meta-analysis. European Journal of Work and Organizational Psychology, 23, 91-106. https://doi.org/10.1080/1359432X.2012.711523

Schwandt, D. R. \& Marquardt, M. J. (2000). Organizational learning: From world-class theories to global best practices. Boca Raton: St Lucie Press.

Schriesheim, C. A., \& DeNisi, A. S. (1980). Item presentation as an influence on questionnaire validity: A field experiment. Educational and Psychological Measurement, 40, 175-182. https://doi.org/10.1177/001316448004000130

Shanock, L. R., \& Eisenberger, R. (2006). When supervisors feel supported: Relationships with subordinates' perceived supervisor support, perceived organizational support, and performance. Journal of Applied Psychology, 91, 689-695. https:// doi.org/10.1037/0021-9010.91.3.689 
Skakon, J., Nielsen, K., Borg, V., \& Guzman, J. (2010). Are leaders' well-being, behaviours and style associated with the affective well-being of their employees? A systematic review of three decades of research. Work and Stress, 24, 107-139. https://doi.org/10.1080/02678373.2010.495262

Smith, G. T., McCarthy, D. M., \& Anderson, K. G. (2000). On the sins of short-form development. Psychological Assessment, 12, 102-111. https://doi.org/10.1037/1040-3590.12.1.102

Stanton, J. M., Sinar, E. F., Balzer, W. K., \& Smith, P. C. (2002). Issues and strategies for reducing the length of self-report scales. Personnel Psychology, 55, 167-194. https://doi.org/10.1111/j.1744-6570.2002.tb00108.x

Tett, R. P., Guterman, H. A., Bleier, A., \& Murphy, P. J. (2000). Development and content validation of a "hyperdimensional" taxonomy of managerial competence. Human Performance, 13, 205-251. https://doi.org/10.1207/ S15327043HUP1303_1

Thoroughgood, C. N., Padilla, A., Hunter, S. T., \& Tate, B. W. (2012). The susceptible circle: A taxonomy of followers associated with destructive leadership. The Leadership Quarterly, 23, 897-917.

Thoroughgood, C. N., Tate, B. W., Sawyer, K. B., \& Jacobs, R. (2012). Bad to the bone: Empirically defining and measuring destructive leader behavior. Journal of Leadership and Organizational Studies, 19, 230-255. https://doi.org/10. $1177 / 1548051811436327$

Tims, M., Bakker, A. B., \& Derks, D. (2012). Development and validation of the job crafting scale. Journal of Vocational Behavior, 80, 173-186. https://doi.org/10.1016/j.jvb.2011.05.009

Tubre, T. C., \& Collins, J. M. (2000). Jackson and Schuler (1985) revisited: A meta-analysis of the relationships between role ambiguity, role conflict, and job performance. Journal of Management, 26, 155-169. https://doi.org/10. 1177/014920630002600104

Widaman, K. F., Ferrer, E., \& Conger, R. D. (2010). Factorial invariance within longitudinal structural equation models: Measuring the same construct across time. Child Development Perspectives, 4, 10-18. https://doi.org/10.1111/j.1750-8606. 2009.00110.x

Widaman, K. F., \& Reise, S. P. (1997). Exploring the measurement invariance of psychological instruments: Applications in the substance use domain. In K. J. Bryant, M. Windle, \& S. G. West (Eds.), The science of prevention: Methodological advances from alcohol and substance abuse research (pp. 281-324). Washington, DC: American Psychological Association.

Wiley, J., \& Kowske, B. (2012). Book highlight? The power of recognition. Global Business and Organizational Excellence, 32(1), 75-84. https://doi.org/10.1002/joe.21465

Wiley, J., \& Lake, F. (2014). Inspire, respect, reward: Re-framing leadership assessment and development. Strategic HR Review, 13, 221-226. https://doi.org/10.1108/SHR-06-2014-0039

Williams, L. J., Hartman, N., \& Cavazotte, F. (2010). Method variance and marker variables: A review and comprehensive CFA marker technique. Organizational Research Methods, 13, 477-514. https://doi.org/10.1177/1094428110366036

Williams, S., Bradley, H., \& Erickson, M. (2013). Globalization and work. Cambridge, England: Polity Press.

Worthington, R. L., \& Whittaker, T. A. (2006). Scale development research: A content analysis and recommendations for best practices. The Counseling Psychologist, 34(6), 806-838. https://doi.org/10.1177/0011000006288127

Yarker, J., Lewis, R., \& Donaldson-Feilder, E. (2008). Management competencies for preventing and reducing stress at work. London, England: HSE Books.

Yukl, G. A. (2012). Effective leadership behaviors: What we know and what questions need more attention? Academy of Management Perspectives, 26(4), 66-85. https://doi.org/10.5465/amp.2012.0088

Yukl, G. A., Gordon, A., \& Taber, T. (2002). A hierarchical taxonomy of leadership behavior: Integrating a half century of behavior research. Journal of Leadership and Organizational Studies, 9(1), 15-32. https://doi.org/10. $1177 / 107179190200900102$

Yukl, G. A., \& Lepsinger, R. (1991). An integrating taxonomy of managerial behavior: Implications for improving managerial effectiveness. In J. W. Jones, B. D. Steffy, \& D. W. Bray (Eds.), Applying psychology in business: The manager's handbook (pp. 563-572). Lexington, MA: Lexington Press.

Yukl, G. A., Mahsud, R., Hassan, S., \& Prussia, G. E. (2013). An improved measure of ethical leadership. Journal of Leadership and Organizational Studies, 20, 38-48. https://doi.org/10.1177/1548051811429352

Yukl, G. A., O'Donnell, M., \& Taber, T. (2009). Influence of leader behaviors on the leader-member exchange relationship. Journal of Managerial Psychology, 24, 289-299. https://doi.org/10.1108/02683940910952697

Yukl, G. A., Wall, S., \& Lepsinger, R. (1990). Preliminary report on validation of the managerial practices survey. In K. E. Clark \& M. B. Clark (Eds.), Measures of leadership (pp. 223-238). West Orange, NJ: Leadership Library of America. Retrieved from. http://ovidsp.ovid.com/ovidweb.cgi?T=JS\&CSC=Y\&NEWS=N\&PAGE=fulltext\&D=psyc3\&AN= 1991-97354-009

\section{AUTHOR'S BIOGRAPHIES}

Dr. Tago L. Mharapara is a recent PhD graduate and Lecturer in the Department of Management at Auckland University of Technology. He completed his doctoral work on positive leader behavior in 2017. Dr. Mharapara's doctoral thesis employed a follower-centric approach to understanding constructive leader behaviors that 
facilitate individual, team and organizational success. Prior to his academic career, Dr. Mharapara worked as an institutional researcher and planner at the College of Saint Benedict and Saint John's University in Minnesota, USA.

Dr. Helena D. Cooper-Thomas is Professor of Organizational Behaviour in the Faculty of Business at Auckland University of Technology. She has authored over 40 peer-reviewed international publications in journals including Journal of Organizational Behavior, Academy of Management Journal, and the Journal of Vocational Behavior. Dr. Cooper-Thomas is Associate Editor on the Journal of Managerial Psychology, on the Consulting Editorial Board of the Journal of Business and Psychology, and a Senior Reviewer for the Journal of Organizational Behavior. Prior to her academic career, Dr. Cooper-Thomas enjoyed a career as a consultant based in London working both independently and for several management consultancies across a range of countries.

Dr. Ann Hutchison is a Senior Lecturer of Management and International Business in the Faculty of Business and Economics at the University of Auckland. As a past HR practitioner, her research has a practical bent, aimed at serving the HR profession. Her research focuses on some core areas of HR delivery: recruitment and selection, staff development, reward and performance management, with a particular context of interest: senior executives. A good deal of her writing focuses on how senior executives can best be selected, developed and rewarded. Dr. Hutchison has published work in Personality and Individual Differences, Asia Pacific Journal of Human Resources, The International Journal of Human Resource Management and Employee Relations: The International Journal.

Dr. Jamie L. Callahan is Professor of Leadership \& Human Resource Development at Northumbria University; she also serves as the Director of Equity and Diversity for the Faculty of Business \& Law. She was Editor-in-Chief for Human Resource Development Review (2011-2014). Her research explores issues of power and privilege in relation to leadership, emotion management and organization contextual issues (e.g., organizational learning, communities of practice). Her most recent co-edited book, Realising Critical HRD: Stories of Reflecting, Voicing, and Enacting Critical Practice, received the Academy of Human Resource Development 2015 R. Wayne Pace Outstanding Book of the Year Award.

How to cite this article: Mharapara TL, Cooper-Thomas HD, Hutchison A, Callahan JL. Assessing constructive supervisor behavior: Development and evaluation of a brief follower-rated scale. Human Resource Development Quarterly. 2019;1-22. https://doi.org/10.1002/hrdq.21339 